\title{
Higher Temperatures Were Closely Associated with Higher Ambulance Transports in Takamatsu Area, Japan
}

\author{
Nobuyuki Miyatake ${ }^{1}$, Masaki Nakao ${ }^{2}$, Noriko Sakano ${ }^{1}$, Shigeru Suna ${ }^{3}$, Takeshi Suzue ${ }^{4}$, \\ Tomohiro Hirao ${ }^{4}$
}

${ }^{1}$ Department of Hygiene, Faculty of Medicine, Kagawa University, Miki, Kagawa, Japan; ${ }^{2}$ Graduate School of Engineering, Osaka City University, Osaka, Japan; ${ }^{3}$ Kagawa Prefectural College of Health Sciences, Japan; ${ }^{4}$ Department of Public Health, Faculty of Medicine, Kagawa University, Miki, Kagawa, Japan.

Email: miyarin@med.kagawa-u.ac.jp

Received October 22 ${ }^{\text {nd }}, 2010$; revised December $9^{\text {th }}, 2010$; accepted January $17^{\text {th }}, 2011$.

\begin{abstract}
The link between high temperatures and ambulance transports in Takamatsu area, Japan was investigated. Monthly observations for ambulance transports (2004-2008) were obtained from Fire Department Service in Takamatsu. Data of temperatures in Takamatsu area, Japan (2004-2008) were used by Japan Meteorological Agency. Effect of high temperatures on ambulance transports was analyzed. By using data from July to September, there were not clear differences of mean temperatures and ambulance transports among years. Ambulance transports were significantly correlated with parameters of temperatures. Correlation coefficient rate between ambulance transports and the mean temperature of maximum temperatures in a month was highest among parameters $(r=0.738, p=0.0017)$. In addition, ambulance transports were also significantly correlated with the number of days over the level of $32^{\circ} \mathrm{C}$ in a month $(r=$ $0.782, p=0.0006)$. Higher temperatures were closely associated with higher ambulance transports in Takamatsu area, Japan.
\end{abstract}

Keywords: Temperature, Ambulance Transports, Takamatsu Area, Fire Department Service in Takamatsu, Japan Meteorological Agency

\section{Introduction}

Global average temperatures are projected to increase between 1.4 and $5.8^{\circ} \mathrm{C}$ by the end of this century [1]. On local and regional scales, changes in land cover can sometimes exacerbate the effect of greenhouse-gas-induced warming, or even exert the largest impact on climatic conditions. Most cities show a large heat island effect, registering $5-11^{\circ} \mathrm{C}$ warmer than surrounding rural areas [2]. An increase in mortality related to heat waves has been reported from various industrialized countries [3-5].

The number of patients with heat stroke is surveyed by National Institute for Environmental Studies in several cities, except Takamatsu area, in Japan [6]. An increase in summer temperatures is likely to increase the number of patients with high temperatures related diseases. Therefore, it is timely to assess local evidence of acute health effects of high temperatures in Takamatsu area,
Japan.

In this study, to address this issue, we investigated monthly ambulance use and its relation to high temperatures in 5 summers in Takamatsu area, Japan.

\section{Methods}

\subsection{Study Area}

Takamatsu area, Kagawa prefecture, Japan, which includes Takamatsu city, Miki-cho and Ayagawa-cho, is on the northern shore of Shikoku Island (in a temperate zone area). The population of Kagawa prefecture is 1000000 and 470000 people are situated on the Takamatsu area. Currently several public offices of Shikoku district are located in Takamatsu city. Although the surrounds of Takamatsu had been used primarily as paddy fields for agriculture, recently they have undergone rapid changes, developing into residential and/or commercial areas. The area's emergency medical services are managed by Fire 
Department Service in Takamatsu and 14 ambulances were in use in 2008 [7].

\subsection{Ambulance Data}

Monthly incidence data of ambulance transports was obtained from Fire Department Service in Takamatsu from July to September for 5 years (2004-2008) [7]. We excluded the number of other ambulance transports i.e. traffic accidents, fire accidents and injuries, and the number of ambulance transports (per a month per ten thousand persons) by acute diseases [8] was used for analysis.

\subsection{Temperatures}

Daily and monthly temperatures in Takamatsu area, Japan for the required periods were obtained from Takamatsu Local Meteorological Observatory, Japan Meteorological Agency [9]. Mean temperature in a month, mean temperature of maximum temperatures in a month, mean temperature of minimum temperatures in a month, maximum temperature in a month, minimum temperature in a month and the number of days over the level of various temperatures in a month were used for analysis.

\subsection{Statistical Analysis}

Simple correlation analysis was used to test the significance of the linear relationship among continuous variables: $p<0.05$ was considered to be statistically significant.

\section{Results}

Changes in mean temperature in a month are summarized in Figure 1. There were not clear differences of mean temperature in a month for 5 years. There were not also clear differences of ambulance transports (per a month per ten thousand persons) for 5 years (Figure 2).

We investigate the relationship between ambulance transports and parameters of temperatures from July to September for 5 years (2004-2008) in Takamatsu area, Japan (Table 1). Ambulance transports were significantly correlated with parameters of temperatures. Correlation coefficient rate between ambulance transports and mean temperature of maximum temperatures in a month was highest among parameters ( $\mathrm{r}=0.738, p=$ 0.0017). The slope of the regression line (changes in mean temperature of maximum temperatures in a month vs changes in ambulance transports) was 0.597 (Figure 3). Accordingly, we found that a $1^{\circ} \mathrm{C}$ in mean temperature of maximum temperatures in a month corresponded to a 0.597 increase in ambulance transports (per a month per ten thousand persons) in Takamatsu area.

In addition, the relation between ambulance transports and the number of days of over the level of various tem-
Table 1. Simple correlation analysis between ambulance transports and parameters of temperatures in Takamatsu area, Japan.

\begin{tabular}{lcc}
\hline & $\mathrm{r}$ & $p$ \\
\hline Mean temperature in a month & 0.728 & $\mathbf{0 . 0 0 2 1}$ \\
Mean temperature of maximum temperatures in a month & 0.738 & $\mathbf{0 . 0 0 1 7}$ \\
Mean temperature of minimum temperatures in a month & 0.668 & $\mathbf{0 . 0 0 6 5}$ \\
maximum temperature in a month & 0.693 & $\mathbf{0 . 0 0 4 2}$ \\
minimum temperature in a month & 0.555 & $\mathbf{0 . 0 3 1 8}$ \\
\hline
\end{tabular}

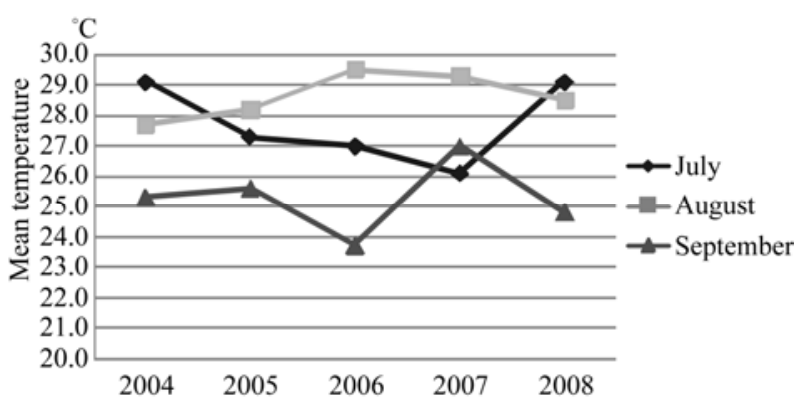

Figure 1. Changes in mean temperature (2004-2008).

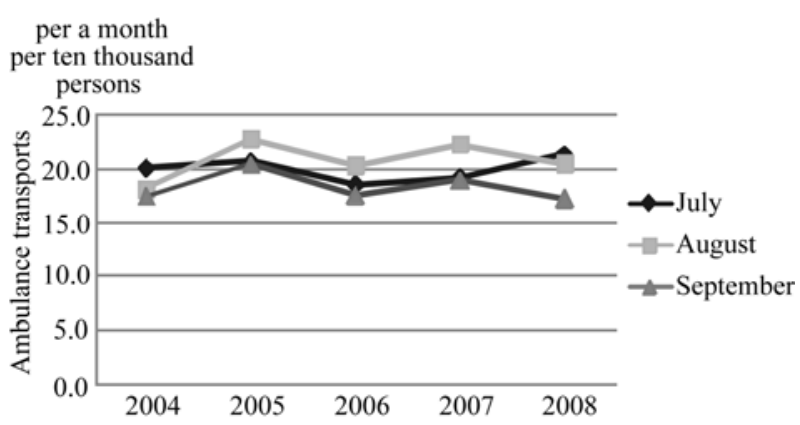

Figure 2. Changes in ambulance transports (2004-2008) (per a month per ten thousand persons).

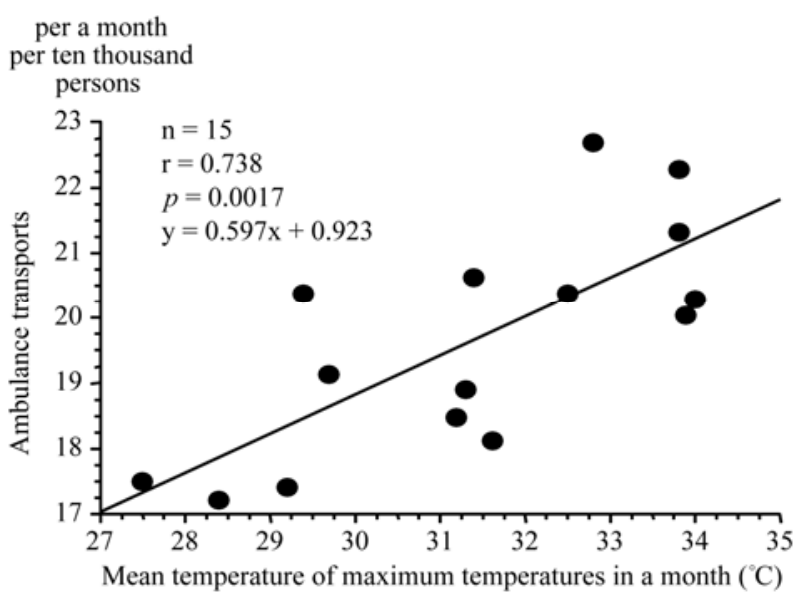

Figure 3. Simple correlation analysis between ambulance transports and mean temperature in a month. 
peratures was also evaluated (Table 2). Ambulance transports were significantly correlated with the number of days of over the level of various temperatures, especially over the level of $32^{\circ} \mathrm{C}(\mathrm{r}=0.782, p=0.0006)$ (Figure 4).

\section{Discussion}

We firstly investigated the link between ambulance transports and parameters of temperatures in Takamatsu area, Japan. Ambulance transports were significantly associated with high temperatures.

In some literatures, the relation between high temperatures and heat stroke in Japan [10-12]. Nakai et al. investigated heat-related deaths in Japan from 1968 through 1994 and heat-related deaths were most prone to occur on days with a peak daily temperature above 38 degrees [10]. In addition, they reported that incidence of heatrelated deaths showed and exponential dependence on the number of hot days [10]. Qui et al. reported that an unusually hot spell in 1999 was followed by a high mortality rate in Hokkaido, Japan [11]. Bai et al. also showed that the number of unusual deaths in the summer of 1994 in Osaka, Japan was more compared to those of previous years [12]. The human body dissipates heat in four ways: convection, conduction, radiation and water evaporation. When the temperature of the surrounding environment is higher than the body temperature, water evaporation is the only way in which the body can dissipate heat. When the air temperature is over 34 degrees, cardiovascular and nervous disorders can occur as a result of problems associated with body temperature adjustment and metabolism of water and salts [11]. Unexpectedly high temperatures are particularly difficult for the elderly [13,14], and chronic diseases [15]. In this study, we investigated the relationship between ambulance transports and parameters of temperatures, and close relationship was noted between ambulance transports and high temperatures in Takamatsu area, Japan. Although, we could not directly evaluate the heat-related diseases or deaths, it seems reasonable to suggest that simply dealing with high temperatures in summer in Takamatsu city i.e. innovation of the thermal energy metabolism in cities and individual coping with high temperatures might result in the amelioration of ambulance transports in Takamatsu area, Japan.

Potential limitations still remain in this study. First, the link between ambulance transports and temperatures, which was noted in this study, may not apply for the link among individuals. Second, we could not directly evaluate heat-related diseases or deaths. Third, daily data of ambulance transports could not obtained in this study. Therefore, we could not accurately evaluate the link between ambulance transports and high temperatures. Fur-
Table 2. Simple correlation analysis between ambulance transports and number of days over the level of various temperatures in a month.

\begin{tabular}{ccc}
\hline & $\mathrm{r}$ & $p$ \\
\hline Number of days over $30^{\circ} \mathrm{C}$ & 0.682 & $\mathbf{0 . 0 0 5 1}$ \\
Number of days over $31^{\circ} \mathrm{C}$ & 0.778 & $\mathbf{0 . 0 0 0 6}$ \\
Number of days over $32^{\circ} \mathrm{C}$ & 0.782 & $\mathbf{0 . 0 0 0 6}$ \\
Number of days over $33^{\circ} \mathrm{C}$ & 0.723 & $\mathbf{0 . 0 0 2 3}$ \\
Number of days over $34^{\circ} \mathrm{C}$ & 0.677 & $\mathbf{0 . 0 0 5 6}$ \\
Number of days over $35^{\circ} \mathrm{C}$ & 0.644 & $\mathbf{0 . 0 0 0 6}$ \\
\hline
\end{tabular}

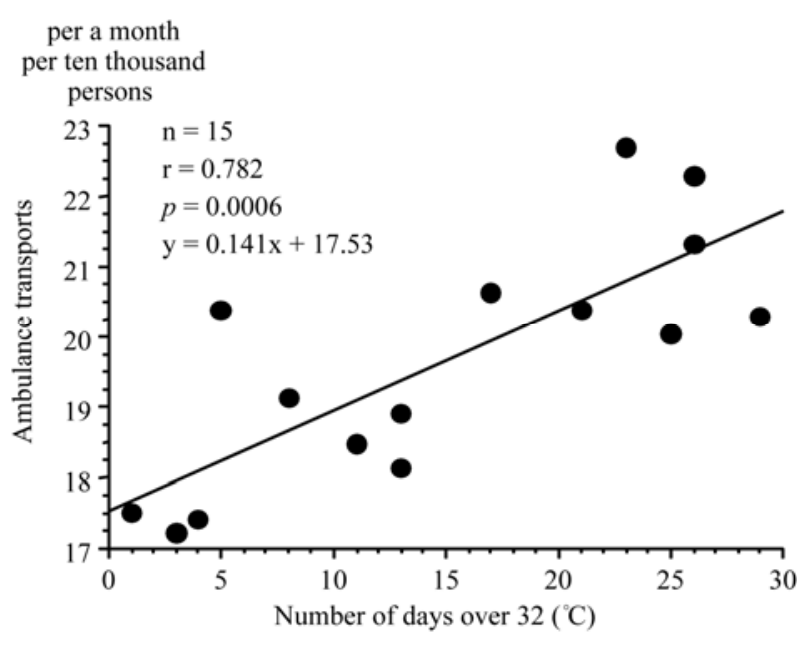

Figure 4. Simple correlation analysis between ambulance transports and the number of days over the level of various temperatures.

ther studies are required to prove such link.

\section{REFERENCES}

[1] "The Scientific Basis: Contribution of Working Group 1 to the Third Assessment Report," Intergovernmental Panel on Climate Change, Climate Change 2001, Cambridge University Press, Cambridge, 2001, pp. 1-944.

[2] C. Aniello, K. Morgan, A. Busbey and L. Newland, "Mapping Micro-Urban Heat Islands Using LANDSAT TM and a GIS,” Computers \& Geosciences, Vol. 21, No. 8, October 1995, pp. 965-969. doi:10.1016/0098-3004(95)00033-5

[3] K. E. Smoyer, “A Comparative Analysis of Heat Waves and Associated Mortality in St. Louis, Missouri - 1980 and 1995,” International Journal of Biometeorology, Vol. 42, No. 1, September 1998, pp. 44-50. doi:10.1007/s004840050082

[4] W. B. Applegate, J. W. Jr. Runyan, L. Brasfield, M. L. Williams, C. Konigsberg and C. Fouche, "Analysis of the 1980 Heat Wave in Memphis," Journal of the American Geriatrics Society, Vol. 29, No. 8, August 1981, pp. 337 - 
342.

[5] M. Lye and A. Kamal, "Effects of a Heatwave on Mortality-Rates in Elderly Inpatients,” Lancet, Vol. 1, No. 8010, March 1977, pp. 529-531.

doi:10.1016/S0140-6736(77)91385-X

[6] “National Institute for Environmental Studies,” 2010. Internet Available: http://www.nies.go.jp/health/HeatStro ke/spot/index.html\#at1 (in Japanese)

[7] “Fire Department Service in Takamatsu, Japan,” 2010. Internet Available: http://www.city.takamatsu.kagawa.jp/ 10991.html (in Japanese)

[8] “Fire and Disaster Management Agency,” 2010. Internet Available: http://aeml.umin.ac.jp/hou/0690.html (in Japanese).

[9] “Japan Meteorological Agency,” 2010. Internet Available: http://www.data.jma.go.jp/obd/stats/etrn/index.php?prec no=72\&prec_ch=\%8D\%81\%90\%EC\%8C\%A7\&block_n o=47891\&block_ch=\%8D\%82\%8F\%BC\&year=\&month $=\&$ day $=\&$ view $=($ in Japanese $)$

[10] S. Nakai, T. Itoh and T. Morimoto, "Deaths from Heat-Stroke in Japan: 1968-1994,” International Journal of Biometeorology, Vol. 43, No. 3, November 1999, pp. 124-127. doi:10.1007/s004840050127

[11] D. Qiu, T. Tanihata, H. Aoyama, T. Fujita, Y. Inaba and
M. Minowa, "Relationship between a High Mortality Rate and Extreme Heat during the Summer of 1999 in Hokkaido Prefecture, Japan,” Journal of Epidemiology, Vol. 12, No. 3, May 2002, pp. 254-257.

[12] H. Bai, M. N. Islam, H. Kuroki, K. Honda and C. Wakasugi, "Deaths Due to Heat Waves during the Summer of 1994 in Osaka Prefecture, Japan, ” Nihon Hoigaku Zasshi, Vol. 49, No. 4, August 1995, pp. 265-274. (in Japanese)

[13] J. B. Worfolk, "Heat Waves: Their Impact on the Health of Elders," Geriatric Nursing, Vol 21, No. 2, March April 2000, pp. 70-77. doi:10.1067/mgn.2000.107131

[14] T. S. Jones, A. P. Liang, E. M. Kibourrne, M. R. Griffin, P. A. Patriarca, S. G. Wassilak, R. J. Mullan, R. F. Herrick, H. D. Jr. Donnell, K. Choi and S. B. Thancker, "Morbidity and Mortality Associated with the July 1980 Heat Wave in St Louis and Kansas City, Mo,” Journal of the American Medical Association, Vol 247, No. 24, June 1982, pp. 3327-3331. doi:10.1001/jama.247.24.3327

[15] J. C. Semenza, C. H. Rubin, K. H. Falter, J. D. Selanikio, W. D. Flanders, H. L. Howe and J. L. Wilhelm, "Heat-Related Deaths during the July 1995 Heat Wave in Chicago," The New England Journal of Medicine, Vol. 335, No. 2, July 1996, pp. 84-90. doi:10.1056/NEJM199607113350203 